\title{
Use of high-speed video recording to detect wing beating produced by honey bees
}

\author{
S. topuch $^{1} \mathbb{D} \cdot$ A. Tofilski $^{1}$
}

Received: 21 March 2018 / Revised: 30 October 2018 / Accepted: 17 November 2018 / Published online: 26 November 2018

(c) The Author(s) 2018

\begin{abstract}
Honey bees use many signals to communicate and coordinate different activities in a colony. In this study, wing and abdomen movements occurring during social interactions between bees were recorded using a high-speed camera. Wing beating was observed in queens, workers and drones. Some of the observed behaviors were reported earlier, but many of them were described here for the first time including drones moving their wings while leaving the nest for mating flights, workers trying to evict them from the nest or in a colony with drone-laying queen, and workers vibrating their wings in contact with a queen outside of the process of swarming, in turns with a shaking signal or while evicting drones from the nest. Queens moved their wings with significantly higher frequency, performing longer pulses of wing beats than drones and workers. Drones vibrated their wings with the frequency similar to workers, but they performed significantly shorter pulses of wing beating. In workers, the frequency of wing beats and the duration of wing-beating pulses were significantly different among various behaviors. Wing beating was performed by bees relatively often in many social contexts and it differed in frequency and pulse duration, which indicates that wing beating may be used for transferring information. High-speed video recording revealed a wide range of new behaviors which may play an important role in honey bee communication. Therefore, it may be used as an alternative or addition to recordings made with microphones and laser vibrometers.
\end{abstract}

Keywords High-speed camera $\cdot$ Honey bee $\cdot$ Social interactions $\cdot$ Wing beats

\section{Introduction}

The western honey bee (Apis mellifera) as a highly social species developed a complex and sophisticated communication system, which allows for coordination of many different activities of thousands of bees in a colony. The bees use many signals, which contain chemical, acoustic, vibratory, tactile or visual cues to transfer information (von Frisch 1967; Michelsen et al. 1987; Tautz 1996; Rohrseitz and Tautz 1999; Thom et al. 2007).

During the swarming season, virgin queens emit two types of piping signals: quacking or tooting. A quacking

Electronic supplementary material The online version of this article (https://doi.org/10.1007/s00040-018-00678-5) contains supplementary material, which is available to authorized users.

S. Łopuch

Sylwia.Lopuch@urk.edu.pl

1 Department of Pomology and Apiculture, Faculty of Biotechnology and Horticulture, University of Agriculture in Kraków, Al. 29 Listopada 54, 31-425 Kraków, Poland is produced by a queen confined in a queen cell, whereas a tooting is produced by a queen who has emerged from her cell (Fletcher 1978; Michelsen et al. 1986b). Queen piping is generated by rapid contractions of the thoracic muscles, and the vibrations are transmitted to the substrate by pressing the thorax against it (Simpson 1964; Kirchner 1993a). Worker piping is produced similarly, however, workers usually pressed their bodies against another bee, but also against the substrate (Seeley and Tautz 2001; Seeley and Visscher 2004; Pierce et al. 2007). Two types of worker piping have been distinguished: wings-together piping (Seeley and Tautz 2001) and wings-apart piping (Ohtani and Kamada 1980; Pratt et al. 1996), which differ in their acoustic properties, production patterns and meaning. The wings-apart pipes are produced in diverse contexts by various types of workers, for instance by foragers (Pratt et al. 1996) or egg-laying workers in queenless colonies (Ohtani and Kamada 1980), whereas the wings-together pipes are produced by nest-site scouts shortly before take-off of a swarm (Seeley and Tautz 2001; Seeley and Visscher 2004; Rangel and Seeley 2008; Rittschof and Seeley 2008). Similar to piping is a stop signal 
(also called a brief piping signal or a begging signal), but it inhibits of bees' activity. A stop signal is emitted in diverse contexts by dance followers, tremble dancers or nest-scouts before swarming to reduce dancing (Esch 1964; Nieh 1993; Michelsen et al. 1986a; Thom et al. 2003; Pastor and Seeley 2005; Schlegel et al. 2012; Seeley et al. 2012; Ramsay et al. 2017). In turn, bee guards produce hissing sounds during aggressive interactions which may deter attack and recruit defending bees (Ohtani and Kamada, 1980; Papachristoforou et al. 2008).

A shaking signal (also called vibration signal, vibratory dance or dorso-ventral abdominal vibration) is produced by a worker bee rapidly vibrating her body dorso-ventrally while grasping another bee or queen cell (Gahl 1975; Fletcher 1978; Seeley et al. 1998; Lewis and Schneider 2000). The vibrated recipients have exhibited greater activity and task performance including foraging, brood care and food processing (Gahl 1975; Painter-Kurt and Schneider 1998a; Seeley et al. 1998; Lewis et al. 2002; Beismeijer 2003). In queens, shaking signals may enhance swarming and mating flights as well as regulate aggressive interactions among virgin queens (Fletcher 1978; Painter-Kurt and Schneider 1998b; Schneider et al. 1998; Seeley et al. 1998; Lewis and Schneider 2000).

Waggle and tremble dances are part of a complex system of regulation of the foraging activity of the honey bee colony (Seeley 1992; Kirchner 1993b). Waggle dances are performed by foragers that returned to their nest to transfer information to their nestmates about the location of important resources including rich food sources or a new nest site (von Frisch 1967). In turn, tremble dances are performed by nectar foragers to recruit other bees to collect nectar from them (Seeley 1992; Thom 2003). Grooming dances perform workers to encourage other workers to clean their bodies (Bozic and Valentincic 1995; Land and Seeley 2004).

The acoustic and vibratory cues appear to be an important component of many signals used by bees in communication including queen and worker piping, stop signal or waggle dance (Wenner 1962a, b; Ohtani and Kamada 1980; Michelsen et al. 1986a, b, 1987; Pratt et al. 1996; Seeley and Tautz 2001; for review see Kirchner 1993a; Hunt and Richard 2013). It has been recently shown that vibrations of various frequencies are produced very often in honey bee colony (Ramsay et al. 2017), however, their meaning remains unknown. The so-called 'dance sounds' produced by dancing honey bees are the best known, and seem to play a substantial role in dance communication because silent dances did not recruit followers at all (Esch 1964; Michelsen and Andersen 1989). The dance sounds are produced as a result of thoracic oscillations generated by the antagonistic indirect flight muscles which induce oscillations of the legs and the wings which transform the thoracic vibrations into substrate vibrations and airborne sounds as well as air jet flows (Simpson 1964; Esch and Wilson 1967; Michelsen et al. 1986b, 1987, 1992; Tautz 1996; Hrncir et al. 2008). Previously, it was demonstrated with the use of microphones and an optical tachometer that the moving wings of dancers were the most likely source of airborne sounds (Michelsen et al. 1987; Spangler 1991). Direct observation by means of a high-speed camera confirmed that honey bees during waggle dances moved their wings, however, we have not measured thoracic vibrations (Łopuch and Tofilski 2017a, b).

Based on our previous results (Łopuch and Tofilski 2017a, b), we have predicted that wing beating may occur during other social interactions between bees. Therefore, social interactions (especially those associated with communication) between honey bee queens, drones and workers were observed with the use of a high-speed camera in different social contexts to better understand their behavior.

\section{Materials and methods}

\section{Samples}

Behaviors of honey bees (A. mellifera) were observed and recorded in three colonies housed in observation hives at the laboratory of the University of Agriculture in Kraków, Poland. The observation hives consisted of six frames. Two of them were located behind glass walls, which allowed recording the bees. These frames contained brood located in their lower part and honey as well as beebread in their upper part. Each colony consisted of about 12,000 bees. Behaviors of honey bee guards were recorded in one colony at the entrance to the hive that consisted of ten frames and about 20,000 bees. This hive was placed outside of the laboratory. The colonies did not show any symptoms of diseases other than a Varroa mite infestation which was mild and controlled by an acaricide. The bees were not individually marked, except for queens.

Queens from three colonies housed in observation hives were observed. In colony 1 , two queens were recorded, one fertile queen which made the unsuccessful attempt of swarming (due to the presence of a queen excluder installed at the nest entrance) and one newly emerged young virgin queen (unmarked) which replaced the old one. At the time of recording of the young queen, there were queen cells present with other queens. In this colony, we recorded queens more than ten times per day, but the precise number of recordings was not logged. In colony 2 , four queens were recorded, one fertile queen which was replaced by the newly emerged young queen (unmarked) as a result of supersedure. Because we wanted to stimulate swarming, the young queen was replaced by the older fertile queen which was replaced, in turn, by the newly emerged young queen (unmarked) as a result of another supersedure. At the time of recording, both 
young queens started laying eggs. In colony 3 , two queens were recorded, the marked fertile queen unexpectedly died on October, and she was replaced by the young virgin queen (unmarked) produced during emergency queen rearing.

\section{Data collection}

Observations of honey bees included social interactions between them with particular reference to bees performing piping, shaking signal, dance, trophallaxis or grooming, but also behaviors accompanying queen replacement (swarming or supersedure), preparing drones for mating flights or evicting drones from the hive. Observations were performed between April and August in queenright colonies with naturally inseminated egg-laying queens unless specified otherwise. Videos were recorded from 10:00 to 17:00. A high-speed camera (Phantom MIRO eX4, Vision Research, Inc. USA) was used. Videos were recorded with the sample rate of $2900 \mathrm{fps}$ at a spatial resolution of $512 \times 384$ pixels and a frame lasted $344.75 \mu$ s. The maximum length of the recording was less than $8 \mathrm{~s}$. Because we focused on recording bees which interacted with other bees, only part of the comb about $5 \times 5 \mathrm{~cm}$ was visible. All episodes of wing beating were analyzed in each of the recording. The video recordings were made and analyzed using PCC software, version 2.6 (Vision Research 2015). All observations were made in daylight. Moreover, a LED lamp (LEDIM616, 50W, Ledim, Poland) was used as light source for video recording, because it does not emit too much heat and does not disturb the behavior of bees by flickering. All applicable international, national, and institutional guidelines for the care and use of animals were followed.

The number of wing beats and the duration of wing beats forming single pulses of wing beating were collected (refer to Fig. 1 in Łopuch and Tofilski 2017b). A wing beat was defined as a complete cycle of wing movement up and down. Honey bees usually performed many successive wing beats forming a pulse (i.e. wing-beating pulse). These pulses were separated by the intervals when their wings were immobile. The interval durations were also collected. The median duration of intervals between wing-beating pulses were calculated based on 4-50 intervals. Similarly, the number and duration of abdomen movements performed during a shaking signal were collected. An abdomen movement was defined as a complete cycle of abdomen movement up and down. The collected data allowed calculating the frequencies of wing beats and abdomen movements performed in different contexts to compare them. Analysis of the video data also included the position of wings and the position of workers in relation to the queens. Honey bees moved folded wings when they kept them close to the abdomen or unfolded wings when they were visibly extended beyond the abdomen. There were also intermediate cases with partly unfolded wings.

\section{Data analysis}

The median values with 25 th-75th percentile were calculated unless specified otherwise. All data were checked for deviation from normality. When deviation from the normal distribution was large, nonparametric tests were used. The parametric $t$ test and one-way ANOVA as well as the non-parametric Mann-Whitney $U$ test and Kruskal-Wallis test were conducted to assess the differences among the analyzed groups. Comparisons included behaviors consisting of ten or more analyzed cases. The homogeneity of variances was estimated by Levene's test. Proportions were compared using a Fisher-Snedecor test, whereas the strength of associations between the analyzed data was assessed by non-parametric Spearman rank correlation. All used tests were two-tailed. All statistical analyses were conducted using Statistica, version 12.0 (Statsoft, 2013). The recorded data was not blind because the observer was not able to assess the parameters of behaviors before their precise analysis.

\section{Results}

\section{Queen wing beats}

Queens usually hold their wings immobile and moved them only in particular situations during swarming and supersedure. Only three of eight queens from three colonies were moving their wings during recording (Online Resource 1). Queens always vibrated folded wings with high frequency (Fig. 1). The wing movements usually formed a series of relatively long pulses, which were separated by a few short ones.

\section{Old queen during the process of swarming}

During the swarming attempt, one fertile queen was recorded more than 10 times per day for 10 days. Over 4 days before an attempt of swarm emergence, only one incidence of wing beating was recorded. After the unsuccessful attempt of swarming and over the next 5 days, wing beating was recorded on 25 recordings.

\section{Young queen during the process of swarming}

Behavior of one young virgin queen which emerged 4 days after the swarming attempt was recorded more than ten times 

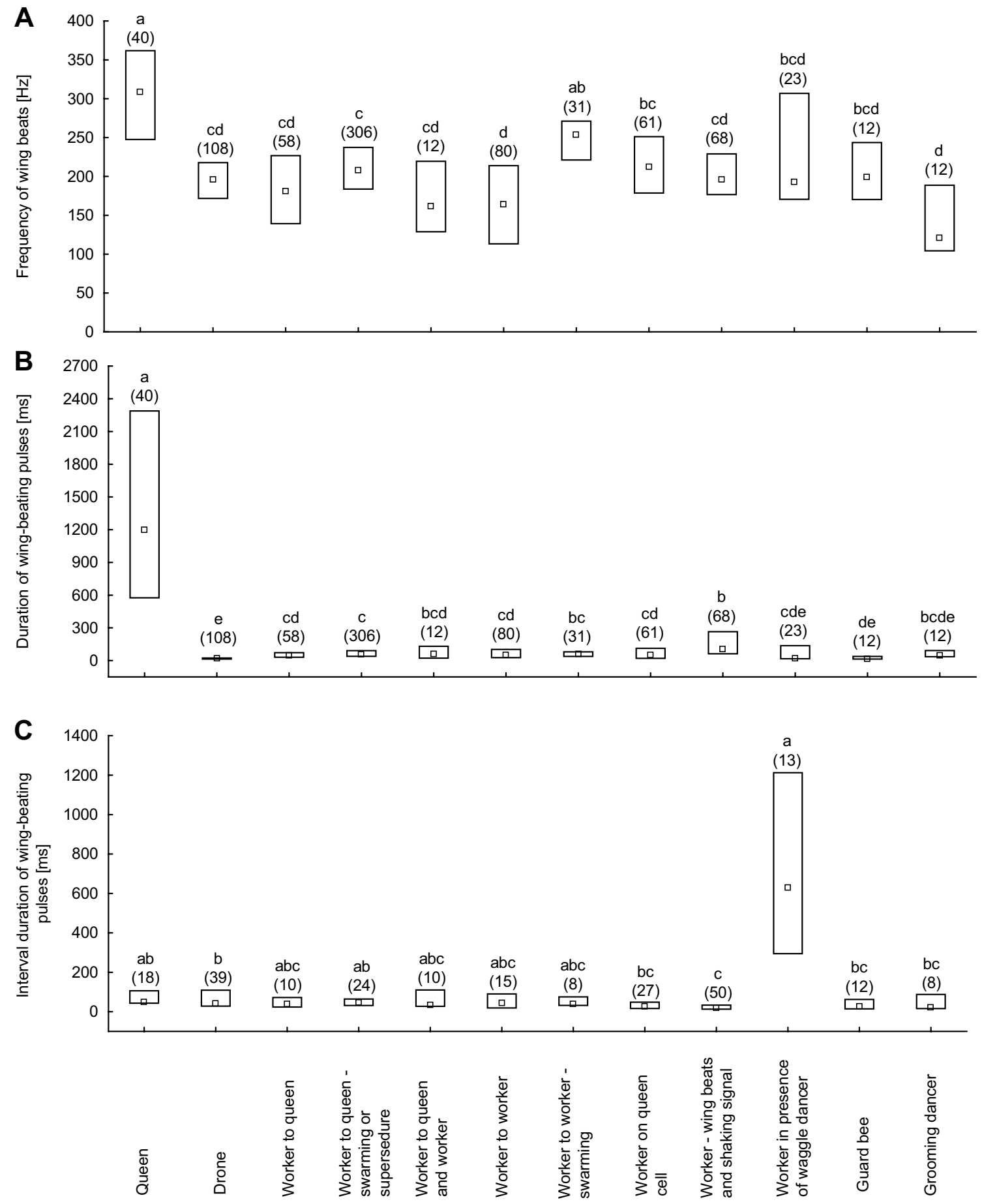

Fig. 1 Frequency of wing beats (A), duration of wing-beating pulses (B) and duration of intervals between wing-beating pulses (C) produced by queens, drones and workers during various behaviors

per day during 9 days after her emergence. During this time, the young queen performed wing beating in 13 recordings. (median \pm 25 th -75 th percentile; in brackets are numbers of analyzed cases, different letters indicate significant differences at $p<0.05$ according to Kruskal-Wallis test)

\section{Young queens during supersedure}

In total, 168 recordings of two young queens from one colony which were produced during supersedure were made 
during 15 days of observations. In those recordings, there was a single incidence of wing beating performed 2 days after emergence.

\section{Old queens outside of swarming process}

In total, we made 474 recordings of three fertile queens from two colonies when their colonies were not preparing for swarming or supersedure during 42 days of observations. No wing beating was observed.

\section{Young queen during emergency queen rearing}

Within 25 recordings of young virgin queen produced during emergency queen rearing, no wing movements was observed. The results are based on 3 days of observations.

\section{Worker wing beats}

\section{Workers in contact with queen or worker or queen cell}

Workers moved their wings mostly during swarming and supersedure usually touching a queen or another worker with their antennae, head, thorax or legs or holding a queen cell on 292 recordings (Online Resource 1). In some cases, more than one worker vibrated their wings on the same video, as a result, 548 cases of wing movements were analyzed. The majority of workers $(66.4 \%, 364$ cases) vibrated their wings touching a queen, fewer moved their wings touching another worker $(20.3 \%, 111$ cases $)$ or holding a queen cell $(11.1 \%$, 61 cases), and occasionally ( $2.2 \%, 12$ cases) they moved their wings while touching both a queen and a worker. Interestingly, there were significant differences in the frequencies of wing beats among workers touching a queen, a worker, both of them or a queen cell [Kruskal-Wallis test: $H$ (3, $N=548)=10.34, p=0.016]$, therefore, they were analyzed separately.

Workers' wing movements while touching a queen (Fig. 1) were usually performed folded wings ( $86.5 \%$ cases), and less often partly unfolded (3.3\% cases) or unfolded (10.2\% cases) wings. Workers more frequently touched a queen's abdomen (57.4\% cases) than her front (i.e. head or thorax; $26.2 \%$ cases) or both of them (i.e. abdomen and front; $16.4 \%$ cases); the difference was significant (Fisher-Snedecor test $G=28.93, p<0.05)$. During the processes of swarming or supersedure (including period of preparation to swarming or supersedure and return to regular functioning of colonies), workers (306 cases) moved their wings with significantly higher frequency ( $t$ test: $t=-2.95, d f=362$, $p=0.003$ ) compared with workers which moved their wings outside of these periods (58 cases), therefore, they were analyzed separately. Similarly, the duration of wingbeating pulses was significantly longer (Mann-Whitney $U$ test: $Z=-2.21 . p<0.001)$ and the number of wing beats per pulse was significantly higher (Mann-Whitney $U$ test: $Z=-3.51, p<0.001$ ) when workers moved their wings during the processes of swarming or supersedure.

Workers while touching another worker (Fig. 1) mostly moved folded wings (61.3\% cases), and less often partly unfolded $(9.0 \%$ cases) or unfolded $(29.7 \%$ cases) wings. The frequency of wing beats and the number of wing beats per pulse were significantly higher $(t$ test: $t=-7.69, d f=109$, $p<0.001$ and Mann-Whitney $U$ test: $Z=-3.42, p=0.001$, respectively) when workers made an attempt of swarming (31 cases) compared with workers which moved their wings outside of the swarming period ( 80 cases). The duration of wing-beating pulses was similar between both groups (Mann-Whitney $U$ test: $Z=-1.11, p=0.268$ ).

Workers in contact with both a queen and a worker (Fig. 1) moved folded (58.3\% cases) or unfolded $(41.7 \%$ cases) wings. Workers sitting on the queen cells (Fig. 1) also moved their wings which were always folded.

\section{Workers performing wing beats in turns with shaking signal or in presence of waggle dancers or during grooming dance}

Honey bee workers sometimes moved wings in turns with performing a shaking signal (Online Resource 2; Fig. 1). This behavior was directed mostly to queens as the majority of workers $(53.0 \%$ cases) vibrated their wings touching a queen, fewer moved their wings holding a queen cell (29.4\% cases), touching another worker (13.2\% cases) or touching both a queen and a worker ( $4.4 \%$ cases). Wing beats were always performed with folded wings. There were no significant differences in the frequency of wing beats in contact with a queen, another worker, both of them or a queen cell (one-way ANOVA: $F_{3,64}=0.73, p=0.539$ ).

Some workers moved folded wings in the presence of waggle dancers producing short pulses of wing beats (Fig. 1). Within 27 recorded grooming dances, wing movements were observed in 12 (44.4\%) cases (Fig. 1). Dancers usually moved unfolded wings performing single short pulses, and some of these pulses were performed using only one wing.

\section{Bee guards and inspected bees}

We have made 54 recordings of guards and arriving workers which were inspected by the guards at the nest entrance. Sometimes more than one bee guard inspected one arriving worker, as a result, 111 cases were analyzed (70 cases of bee guards and 41 cases of inspected workers). Both bee guards (38 cases, $54.3 \%$ ) and inspected bees (15 cases, 36.6\%) vibrated their wings. Workers moved folded or unfolded wings as they often started vibrating folded wings, but 
they spread them later. Based on the analyzed data of wing movements ( 16 cases), there was no significant difference between bee guards (12 cases; Fig. 1) and inspected bees (four cases) in the frequency of wing beats (test $t: t=-0.20$, $d f=14, p=0.843$ ). In the case of inspected bees, the median frequency of wing beats was $219.6(213.95-234.04) \mathrm{Hz}$, whereas the median duration of wing-beating pulses was 15.8 (14.34-18.78) ms. The median duration of intervals between pulses was $21.8(12.30-38.75) \mathrm{ms}$.

\section{Workers evicting drones}

We have made 34 recordings of workers which evicted drones from their colony. The wing movements were observed in workers (three cases, $8.8 \%$ ) and drones (four cases, $10.8 \%$ ). Both workers and drones moved folded wings. In case of workers, the median frequency of wing beats was $126.0(118.09-135.04) \mathrm{Hz}$ with the median duration of wing-beating pulses of 28.6 (27.42-31.25) $\mathrm{ms}$. The median duration of intervals between pulses was $22.6(17.08-34.93) \mathrm{ms}$. In the case of drones, the median frequency of wing beats was $199.3(130.34-277.12) \mathrm{Hz}$ with the median duration of wing-beating pulses of 25.9 (17.15-34.94) ms. The median duration of intervals between pulses was $12.2(7.93-19.40) \mathrm{ms}$.

\section{Behaviors rarely accompanied by wing beating}

Wing beats were observed only in the case of $5(6.6 \%)$ of 76 recordings of tremble dance. Dancers usually moved unfolded wings performing single short pulses of wing beating. The median frequency of wing beats was 104.4 (100.41-210.00) Hz, whereas the median duration of wing-beating pulses was $16.2(15.86-50.05) \mathrm{ms}$. Within 52 recordings of trophallaxis, 36 of them were between two workers, nine between worker and queen and seven between worker and drone. Only in one case of trophallaxis between worker and drone, the latter slightly moved his folded wings performing one pulse consisting of two wing beats. Within 18 recordings of grooming, there was one case when one bee was groomed by three other bees. None of the grooming workers moved their wings during this behavior, but there were two cases of 18 recorded when groomed workers moved unfolded wings performing single short pulses.

\section{Drone wing beats}

Drones usually did not move their wings and hold them immobile. They vibrated them only in exceptional situations (Online Resource 3) such as preparing to mating flights. Within 108 cases of recordings, the wing movements were observed in $47.2 \%$ of cases (Fig. 1). Drones collected some honey and after that they usually started moving their wings walking or running to the beehive entrance. Based on the analyzed data of wing movements ( 37 cases), drones usually vibrated folded wings ( $83.3 \%$ cases), and less often unfolded ( $10.8 \%$ cases) or partly unfolded $(5.4 \%$ cases) wings.

Within 126 cases of recordings of drones in colony 1 (25 cases) and colony 2 (101 cases) with fertile queens, none of the drones moved their wings. We have also made 45 recordings of drones in one colony with drone-laying queen. The wing movements were observed only in two (4.4\%) cases. The median frequency of wing beats was 170.9 (167.17-174.68) Hz with the median duration of wing-beating pulses of 15.6 (13.63-17.66). The median duration of intervals between pulses was $25.0(19.41-30.65) \mathrm{ms}$.

\section{Worker abdomen movements}

A shaking signal performed in turns with wing beats (Fig. 2) was directed mostly to a queen, but also to another worker, both a queen and a worker, or a queen cell. There were no significant differences in the frequencies of abdomen movements among these groups [Kruskal-Wallis test: $H(3$, $68)=4.92, p=0.178]$. A shaking signal performed in turns with waggle dance was recorded only eight times (Fig. 2).

Workers also performed a shaking signal alone touching or holding a queen $(21.2 \%, 32$ cases $)$, worker $(30.5 \%, 46$ cases), comb $(15.2 \%, 23$ cases $)$ or queen cell $(33.1 \%, 50$ cases). There were significant differences in the frequencies of shaking signal among mentioned groups [Kruskal-Wallis

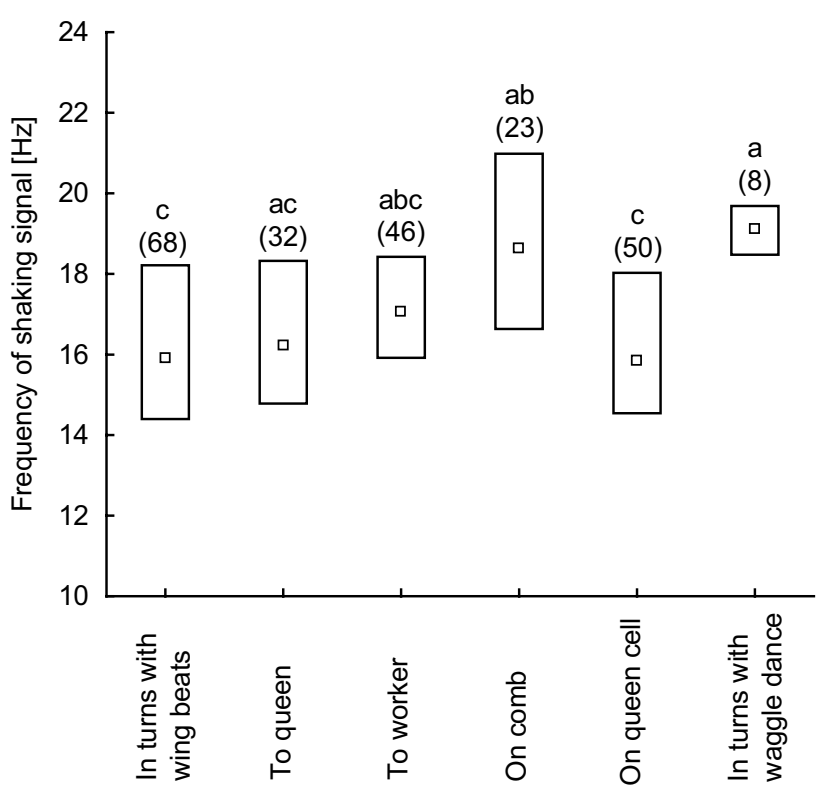

Fig. 2 Frequency of shaking signal performed by workers during different behaviors (median \pm 25 th-75th percentile; in brackets are numbers of analyzed cases, different letters indicate significant differences at $p<0.05$ according to Kruskal-Wallis test) 
test: $H(3, N=151)=16.39, p=0.001]$, therefore they were analyzed separately (Fig. 2).

\section{Comparisons of wing beating and shaking signals produced during different behaviors}

Honey bees moved their wings during various social interactions. Comparisons among them showed that there were significant differences in the frequencies of wing beats [Kruskal-Wallis test: $H(11, N=740)=141.89, p<0.001$; Fig. 1a]. Queens moved their wings with significantly higher frequency compared with workers and drones $(p<0.05)$, except for wing beats performed by workers during swarming $(p>0.05)$. Drones moved their wings with the frequency similar to workers $(p>0.05)$, except for wing beats performed by workers during swarming $(p<0.001)$. In workers, there were significant differences between various behaviors $(p<0.05)$.

Significant differences were also found in the duration of wing-beating pulses [Kruskal-Wallis test: $H(11$, $N=740)=192.32, p<0.001$; Fig. 1b] and the number of wing beats per single pulse [Kruskal-Wallis test: $H(11$, $N=740)=200.24, p<0.001]$ among castes and different behaviors. The pulses of wing beating performed by queens were significantly longer than the pulses performed by drones and workers $(p<0.01)$. The duration of wing-beating pulses performed by drones also differed significantly from those performed by workers $(p<0.05)$, except for pulses of wing beats performed in the presence of waggle dancers, as well as by bee guards and grooming dancers $(p>0.05)$. Among workers, the wing-beating pulses significantly differed in their duration depending on the type of behavior $(p<0.05)$. In the case of the number of wing beats per pulse, differences among castes and different behaviors were very similar to those described above as there was a very strong correlation between the duration of wing-beating pulses and the number of wing beats per pulse $\left(r_{\mathrm{S}}=0.95, p<0.001\right.$, $N=740$ ).

There were also significant differences in the duration of intervals between pulses of wing beating during different types of behaviors [Kruskal-Wallis test: $H(11$, $N=234)=54.52, p<0.001$; Fig. 1c]. The duration of intervals between pulses was significantly higher in the case of wing beating performed in the presence of waggle dancers and in a sequence with shaking signal compared with the duration of intervals between pulses performed by queens, drones and workers in the case of wing beats directed to a queen during queen replacement or a queen cell, as well as performed by bee guards and grooming dancers $(p<0.05)$.

Significant differences were also found in the frequencies of abdomen movements [Kruskal-Wallis test: $H(5$, $N=227)=26.14, p<0.001$; Fig. 2]. Shaking signals performed by workers holding a comb or in turns with waggle dance had a significantly higher frequency than shaking signals performed by workers holding a queen cell or in turns with wing beats $(p<0.05)$.

\section{Discussion}

Use of high-speed video recording allowed us to observe honey bee wing movements in many different social contexts which suggests that wing beating play a role in social interactions. The wing movements were recorded in queens during swarming or supersedure, drones preparing for mating flights or evicted from the nest by workers or those from a colony with drone-laying queen, workers performing wing beats in turns with shaking signal or in contact with a queen and other workers during swarming or supersedure as well as outside of swarming period or on queen cells or in the presence of waggle dancers or during grooming dance or by guards at the beehive entrance or evicting drones from the nest or inspected by guards at the beehive entrance. Observations also showed that not all honey bee behaviors are associated with wing movements because during tremble dance, grooming or trophallaxis bees did not move their wings or only sporadically. Previously, we showed that dancing workers also moved their wings, mostly during the waggle phase of dance (Łopuch and Tofilski 2017a, b), which is the most important for information transfer (von Frisch and Jander 1957). All these findings suggest that wing beating is not a by-product of other behaviors. Moreover, it is unlikely that the wing vibrations serve warming up the flight muscles before the flight out because it was shown that bees can warm up silently, with no thoracic vibrations or wing movements (Heinrich and Esch 1994).

Importantly, the frequency and temporal structure of wing-beating pulses were considerably different among bees interacted with each other in various behavioral contexts which indicates that they are specific. Queens always moved folded wings performing slight movements with the frequency of $299 \mathrm{~Hz}$. Pulses of wing beating were usually long consisting of hundreds of wing movements, however, such long pulses were often separated by very short ones that consisted of only a few wing beats. Drones produced wing beating clearly different from that generated by queens, as they moved usually folded wings with significantly lower frequency of $190 \mathrm{~Hz}$ and produced shorter pulses lasting $33 \mathrm{~ms}$ and consisting of a few wing beats. Workers moved their wings in various situations during interactions with queens, drones and other workers. They vibrated wings with significantly lower frequency than queens, and the pulses of wing beating were also considerably shorter. The wingbeating pulses generated by workers were more similar to those produced by drones in the case of the frequency of 
wing beats, but they significantly differed in the duration of wing-beating pulses which was longer.

Described differences in the frequency and duration of wing-beating pulses were accompanied by differences in bees' behaviors. Queens moved their wings only during queen replacement period. Similarly, drone wing-beating was observed only in specific situations including preparation for mating flight or eviction from the nest by workers or in a colony with drone-laying queen. In the case of workers, the frequencies and durations of wing beating differed depending on the presence of queen or worker or drone, and whether or not queen replacement took place, as well as behavioral context (f. ex. wing beating in the presence of waggle dancers or guards), which indicates that their meaning may differ. Previously, it was demonstrated that wing beating may play some role in dance communication of honey bees because the combined duration of wing beating and the number of wing-beating pulses were strongly positively correlated with the duration of waggle phase and the number of abdomen waggles in the waggle phase (Eopuch and Tofilski 2017a, b), which transfer information about the distance from the nest to the food source (von Frisch and Jander 1957). It is worth noting that wing movements were recorded mostly during important for honey bee colony events such as queen replacement or mating flights. Because the duration of intervals occurring between pulses of wing beats was similar in various behaviors, they probably do not play a role in information transfer. Because weather conditions may affect on sounds emitted by honey bees especially foragers (Wenner et al. 1967; Tlačbaba et al. 2014), it is possible that they might influence wing movements in the present study. However, their impact on the frequency and temporal structure of wing beating should not be considerable because of large number of recordings made inside of observation hives placed inside the laboratory during four months. Nevertheless, this issue needs additional research.

Interestingly, we were able to observe wing movements in many contexts in which sounds and vibrations were reported including young queens during swarming (Wenner 1962a; Fletcher 1978; Grooters 1987; Michelsen et al. 1986b), workers performing waggle dance (Wenner 1962b; Michelsen et al. 1986a; Waddington and Kirchner 1992), and stop signal (Michelsen et al. 1986a; Kirchner 1993b; Thom et al. 2003; Schlegel et al. 2012), workers before leaving the nest with a swarm (Rangel et al. 2010), guards (Ohtani and Kamada 1980), and foragers (Pratt et al. 1996). There were also similarities between the characteristics of wing beats and sounds or vibrations, as well as similarities in behaviors and contexts when wing beating was observed, and sounds or vibrations were reported. For example, we recorded wing movements performed by queens only during queen replacement period. They moved folded wings with high frequency
$(299 \mathrm{~Hz})$, and the wing-beating pulses were long (1.6 s). Previously, it was reported that young virgin queens produced a piping during swarming with the frequency ranging from 300 to $500 \mathrm{~Hz}$. Queens during piping performed slight movements with folded wings, and recorded pipes were long as the initial pipe might last $1 \mathrm{~s}$ or more, whereas the following pipes were usually shorter and lasted about $0.25 \mathrm{~s}$ (Hansson 1945 cited by Grooters 1987; Wenner 1962a; Fletcher 1978; Michelsen et al. 1986b; Grooters 1987). Another example is behavior of some workers which moved folded wings with high frequency $(224 \mathrm{~Hz})$ performing very short $(60 \mathrm{~ms})$ pulses of wing beating in the presence of waggle dancers. This behavior reminds stop signal reported in other studies because it had a high fundamental frequency ranging from 270 to $540 \mathrm{~Hz}$ and it was short lasting from 50 to $700 \mathrm{~ms}$ (on average 60-240 ms; Esch 1964; Michelsen et al. 1986a; Kirchner 1993b; Thom et al. 2003; Schlegel et al. 2012; Seeley et al. 2012). Moreover, most of stop signals were produced by dance followers to waggle dancers or nest-scout bees to inhibit dance (Nieh 1993; Schlegel et al. 2012; Seeley et al. 2012). Described similarities may indicate that the wing-beating pulses reported in the present study correspond to the sound or vibratory pulses reported in the cited studies. It is possible because wing movements are produced by the same flight muscles which are the source of sounds and vibrations detected with the use of microphones or vibrometers (Simpson 1964; Esch and Wilson 1967; Michelsen et al. 1986b, 1987; Tautz 1996; Hrncir et al. 2008). Recently, the vibrations of thorax and wingtip were simultaneously recorded with the use of two laser vibrometers, and the thorax vibrations were highly correlated with those of wingtips during annoyance buzzing and forager vibrations in a stingless bee (Melipona seminigra) (Hrncir et al. 2008). The wing movements were also reported during sound emission (i.e. piping) by virgin queens and some foragers (Hansson 1945 cited by Grooters 1987; Pratt et al. 1996). Nevertheless, we did not measure the thoracic vibrations simultaneously with the wing beating in honey bees, therefore, this prediction needs to be proved. However, it is unlikely that wing movements occur without thoracic vibrations caused by flight muscles.

The majority of research concerning honey bee communication was performed indirectly using microphones (Wenner 1962a, b; Esch 1964; Simpson 1964; Ohtani and Kamada 1980; Michelsen et al. 1986a, b, 1987; Kirchner 1993b; Pratt et al. 1996; Seeley and Tautz 2001; Pastor and Seeley 2005), an optical tachometer with a photodiode (Spangler 1991), a hot-wire anemometer (Michelsen 2003), or an accelerometer (Ramsay et al. 2017). Direct measurements with the use of a laser vibrometer were rare (Michelsen et al. 1986a, b; Hrncir et al. 2011). Observation by means of a high-speed camera proved to be useful for detecting wing movements during waggle dance (Eopuch and Tofilski 2017a, b), and in 
the present study. Moreover, high-speed video recording has some advantages over other methods used to study sounds and vibrations produced by bees because it allows to determine the source of sounds and vibrations more precisely. In a honey bee colony, there is usually a crowd of individuals and it is not always clear which of them produced the sounds or vibrations. Moreover, wing movements and accompanying behavior can be observed directly which allows more precise description. When microphones are used, the wing or thorax movements are detected indirectly by recording sounds produced by them. Sound propagation is a complex phenomenon involving reflection, interference and attenuation,. Therefore, some sounds can be difficult to distinguish from the background noise (Wenner et al. 1967). Disadvantage of high-speed video recording is short time of recording. Nevertheless, high-speed video recording may be useful as an alternative or addition to recordings made with microphones and laser vibrometers.

In this study, we also conducted a detailed analysis of shaking signal which is performed by workers in many behavioral contexts (Gahl 1975; Fletcher 1978; Seeley et al. 1998; Lewis and Schneider 2000). The frequency of vibrations ranged from 16 to $19 \mathrm{~Hz}$, and it was slightly higher than in Gahl's study (1975) where the frequency was $16 \mathrm{~Hz}$. A shaking signal was performed mostly on other bees (workers or queens), and less often on the comb what is consistent with other observations (Gahl 1975). Interestingly, the frequency of vibrations performed on the comb was higher than these directed to queens or workers. It is likely that vibrations are more easily transmitted directly to another bee by contact than indirectly by the comb. Occasionally, a shaking signal was performed in turns with wing beating, but such behavior was always directed to other bees, and it was never performed on the comb.

Wing beating can be perceived by honey bees in various ways. Bees moving their wings usually touched another bee, therefore, the thoracic vibrations causing wing movements can be detected directly through contact. Moreover, it is possible that the wing muscles generate substrate vibrations and moving wings produce airborne sounds which are detectable by bees. The wing movements also generate jet air flows (Michelsen et al. 1986a, 1987, 1992), which may diffuse olfactory signals (Thom et al. 2007). Various behavioral contexts differed in the frequency and temporal structure of wing-beating pulses. Comparison of different behaviors revealed that they are specific. Therefore, it is probable that bees are able to use the wing beating for providing information about the behavioral context in which they happen. Common use of wing movements by interacting bees seems to support this assumption.

\section{Conclusions}

Analyses of high-speed video recordings revealed new details concerning honey bee behavior. We have demonstrated that wing beating is performed by bees relatively often in many different social contexts. Some of the behaviors were recorded here for the first time, for instance drone wing beating or worker wing beating in turns with shaking signal. These findings indicate that honey bee communication still holds many mysteries, and the use of high-speed recording may help to reveal them and make them better understood.

Acknowledgements We would like to thank Łukasz Bednarz from EC Test Systems for technical assistance. This study was funded by the National Science Centre under Grant DEC-2013/10/E/NZ9/00682.

\section{Compliance with ethical standards}

Conflict of interest The authors declare that they have no conflict of interest.

OpenAccess This article is distributed under the terms of the Creative Commons Attribution 4.0 International License (http://creativeco mmons.org/licenses/by/4.0/), which permits unrestricted use, distribution, and reproduction in any medium, provided you give appropriate credit to the original author(s) and the source, provide a link to the Creative Commons license, and indicate if changes were made.

\section{References}

Biesmeijer JC (2003) The occurrence and context of the shaking signal in honey bees (Apis mellifera) exploiting natural food sources. Ethology 109:1009-1020

Bozic J, Valentincic T (1995) Quantitative analysis of social grooming behavior of the honey bee Apis mellifera carnica. Apidologie 26:141-147

Esch H (1964) Beiträge zum Problem der Entfernungsweisung in den Schwänzeltänzen der Honigbiene. Z Vergl Physiol 48:534-546

Esch H, Wilson D (1967) The sounds produced by flies and bees. Z Vergl Physiol 54:256-267

Fletcher DJC (1978) Vibration of queen cells by worker honeybees and its the issue of swarms with virgin queens. J Apic Res 17:14-26

Gahl RA (1975) The shaking dance of honey bee workers: evidence for age discrimination. Anim Behav 23:230-232

Grooters HJ (1987) Influences of queen piping and worker behaviour on the timing of emergence of honey bee queens. Insect Soc 34:181-193

Heinrich B, Esch H (1994) Thermoregulation in bees. Am Nat $82: 164-170$

Hrncir M, Gravel AI, Schorkopf DLP, Schmidt VM, Zucchi R, Barth FG (2008) Thoracic vibrations in stingless bees (Melipona seminigra): resonances of the thorax influence vibrations associated with flight but not those associated with sound production. J Exp Biol 211:678-685

Hrncir M, Maia-Silva C, Mc Cabe SI, Farina WM (2011) The recruiter's excitement - features of thoracic vibrations during the honey 
bee's waggle dance related to food source profitability. J Exp Biol 214:4055-4064

Hunt JH, Richard FJ (2013) Intracolony vibroacoustic communication in social insects. Insect Soc 60:403-417

Kirchner WH (1993a) Acoustical communication in honeybees. Apidologie 24:297-307

Kirchner WH (1993b) Vibrational signals in the tremble dance of the honeybee Apis mellifera. Behav Ecol Sociobiol 33:169-172

Land BB, Seeley TD (2004) The grooming invitation dance of the honey bee. Ethology 110:1-10

Lewis LA, Schneider SS (2000) The modulation of worker behavior by the vibration signal during house hunting in swarms of the honeybee, Apis mellifera. Behav Ecol Sociobiol 48:154-164

Lewis LE, Schneider SS, Degrandi-Hoffman G (2002) Factors influencing the selection of recipients by workers performing vibration signals in colonies of the honeybee, Apis mellifera. Anim Behav 63:361-367

Łopuch S, Tofilski A (2017a) Direct visual observation of wing movements during the honey bee waggle dance. J Insect Behav 30:199-210

Łopuch S, Tofilski A (2017b) Importance of wing movements for information transfer during honey bee waggle dance. Ethology 123:974-980

Michelsen A (2003) Signals and flexibility in the dance communication of honeybees. J Comp Physiol A 189:165-174

Michelsen A, Andersen BB (1989) Honeybees can be recruited by a mechanical model of a dancing bee. Naturwissenschaften 76:277-280

Michelsen A, Kirchner WH, Lindauer M (1986a) Sound and vibrational signals in the dance language of the honeybee, Apis mellifera. Behav Ecol Sociobiol 18:207-212

Michelsen A, Kirchner WH, Andersen BB, Lindauer M (1986b) The tooting and quacking vibration signals of honeybee queens: a quantitative analysis. J Comp Physiol A 158:605-611

Michelsen A, Towne WF, Kirchner WH, Kryger P (1987) The acoustic near field of a dancing honeybee. $J$ Comp Physiol A 161:633-643

Michelsen A, Andersen BB, Storm J, Kirchner WH, Lindauer M (1992) How honeybees perceive communication dances, studied by means of a mechanical model. Behav Ecol Sociobiol 30:143-150

Nieh JC (1993) The stop signal of honey bees: reconsidering its message. Behav Ecol Sociobiol 33:51-56

Ohtani T, Kamada T (1980) Worker piping: the piping sounds produced by laying and guarding worker honeybees. J Apic Res 19:154-163

Painter-Kurt S, Schneider SS (1998a) Age and behavior of honey bees, Apis mellifera (Hymenoptera: Apidae), that perform vibration signals on workers. Ethology 104:457-473

Painter-Kurt S, Schneider S (1998b) Age and behavior of honey bees, Apis mellifera (Hymenoptera: Apidea), that perform vibration signals on queens and queen cells. Ethology 104:475-485

Papachristoforou A, Sueur J, Rortais A, Andelopoulos S, Thrasyvoulou A, Arnold G (2008) High frequency sounds produced by Cyprian honeybees Apis mellifera cypria when confronting their predator, the Oriental hornet Vespa orientalis. Apidologie 39:468-474

Pastor KA, Seeley TD (2005) The brief piping signal of the honey bee: begging call or stop signal? Ethology 111:775-784

Pierce AL, Lewis LA, Schneider S (2007) The use of the vibration signal and worker piping to influence queen behavior during swarming in honey bees, Apis mellifera. Ethology 113:267-275

Pratt SC, Kühnholz S, Seeley TD, Weidenmüller A (1996) Worker piping associated with foraging in undisturbed queenright colonies of honey bees. Apidologie 27:13-20

Ramsay M, Bencsik M, Newton MI (2017) Long-term trends in the honeybee 'whooping signal' revealed by automated detection. Plos One 12:e0171162
Rangel J, Seeley TD (2008) The signals initiating the mass exodus of a honeybee swarm from its nest. Anim Behav 76:1943-1952

Rangel J, Griffin SR, Seeley TD (2010) Nest-site defense by competing honey bee swarms during house-hunting. Ethology 116:608-618

Rittschof CC, Seeley TD (2008) The buzz-run: how honeybees signal 'Time to go!'. Anim Behav 75:189-197

Rohrseitz K, Tautz J (1999) Honey bee dance communication: waggle run direction coded in antennal contacts? J Comp Physiol A 184:463-470

Schlegel T, Visscher PK, Seeley TD (2012) Beeping and piping: characterization of two mechano-acoustic signals used by honey bees in swarming. Naturwissenschaften 99:1067-1071

Schneider SS, Visscher PK, Camazine S (1998) Vibration signal behavior or waggle-dancers in swarms of the honey bee, Apis mellifera (Hymenoptera: Apidea). Ethology 104:963-972

Seeley TD (1992) The tremble dance of the honey bee: message and meanings. Behav Ecol Sociobiol 31:375-383

Seeley TD, Tautz J (2001) Worker piping in honey bees swarms and its role in preparing for liftoff. J Comp Physiol A 187:667-676

Seeley T, Visscher PK (2004) Group decision making in nest-site selection by honey bees. Apidologie 2044:101-116

Seeley TD, Weidenmuller A, Kuhnholz S (1998) The shaking signal of the honey bee informs workers to prepare for greater activity. Ethology 104:10-26

Seeley TD, Visscher PK, Schlegel T, Hogan PM, Franks NR, Marshall JAR (2012) Stop signals provide cross inhibition in collective decision-making by honeybee swarms. Science 335:108-111

Simpson J (1964) The mechanism of honey-bee queen piping. Z Vergl Physiol 48:277-282

Spangler HG (1991) Do honey bees encode distance information into the wing vibrations of the waggle dance. J Insect Behav 4:15-20

Statsoft I (2013) Statistica (data analysis software system), version 12.0. http://www.statsoft.com. Accessed 19 Mar 2018

Tautz J (1996) Honeybee waggle dance: recruitment success depends on the dance floor. J Exp Biol 199:1375-1381

Thom C (2003) The tremble dance of honey bees can be caused by hive-external foraging experience. J Exp Biol 206:2111-2116

Thom C, Gilley DC, Tautz J (2003) Worker piping in honey bees (Apis mellifera): the behavior of piping nectar foragers. Behav Ecol Sociobiol 53:199-205

Thom C, Gilley DC, Hooper J, Esch HE (2007) The scent of the waggle dance. PloS Biology 5:e228

Tlačbaba J, Černŷ M, Dostál M, Přidal A (2014) The acoustic emission in the nest on the honey bee depending on the extreme weather conditions. Acta Univ Agric Silvic Mendel Brun 62:245-254

Vision Research, Inc (2015) PCC software, version 2.6. http://www. visionresearch.net. Accessed 19 Mar 2018

von Frisch K (1967) The dance language and orientation of bees. Harvard University Press, Cambridge

von Frisch K, Jander R (1957) Über die Schwänzeltanz der Bienen. Z Vergl Physiol 40:239-263

Waddington KD, Kirchner WH (1992) Acoustical and behavioral correlates of profitability of food sources in honey bee round dances. Ethology 92:1-6

Wenner AM (1962a) Communication with queen honey bee by substrate sound. Science 138:446-448

Wenner AM (1962b) Sound production during the waggle dance of the honey bee. Anim Behav 10:79-95

Wenner AM, Wells PH, Rohlf FJ (1967) An analysis of the waggle dance and recruitment in honey bees. Physiol Zool 40:317-344 